\title{
A Conversation Between Howard Soule and Johannes Czernin
}

\author{
Howard R. Soule ${ }^{1}$ and Johannes Czernin ${ }^{2}$ \\ ${ }^{I}$ Prostate Cancer Foundation, Santa Monica, California; and ${ }^{2}$ David Geffen School of Medicine at UCLA, Los Angeles, California
}

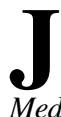
ohannes Czernin, MD, editor-in-chief of The Journal of Nuclear Medicine, talked with Howard R. Soule, PhD, Executive Vice President and Chief Science Officer for the Prostate Cancer Foundation (PCF; Santa Monica, CA), about the challenges associated with supporting and encouraging research in an environment of rapidly changing scientific knowledge and clinical practice. Dr. Soule coordinates global academic, government, and biopharmaceutical sector research activity for the PCF and is responsible for implementation of PCF's global research strategies. He is also a member of the Department of Defense (DOD) Prostate Cancer Research Program Integration Panel. Dr. Soule received his $\mathrm{PhD}$ from Baylor College of Medicine (Houston, TX) in virology and epidemiology and was a postdoctoral fellow in immunology and vascular biology at the Scripps Research Institute (La Jolla, CA). Before joining PCF in 1997, he was a senior R\&D executive for 9 years at Corvas International Inc. (San Diego, CA), a public biotechnology company. He was responsible for the discovery and development of innovative products for treatment of life-threatening cardiovascular diseases. He has also served as managing director of Knowledge Universe Health and Wellness Group, a private investment firm focused on companies in disease prevention and treatment.

Dr. Czernin: Thank you, Howard, for agreeing to talk to our readers and me. You serve as Executive Vice President and Chief Science Officer of the PCF. Can you tell us about your background as a scientist and how you translated your education into leading the scientific program of the PCF?

Dr. Soule: $\mathrm{My} \mathrm{PhD}$ is actually in virology and epidemiology. I still follow the field, especially today with viral epidemics. But I changed my direction and came to California first as a postdoctoral fellow at the Research Institute of Scripps Clinic. I studied vascular biology and immunology and was involved in some of the first cancer imaging studies with a breast cancer monoclonal antibody. When I finished my postdoc, there was an explosion of opportunity in the biotechnology industry. I decided to work for a diagnostic company for several years. It was a great experience on how to take laboratory findings and turn them into something that's useful for patients-a process that lives within me to this day.

Thomas Edgington, my mentor at Scripps, was first to clone the molecule that we know as human tissue factor. He started a company that I joined as the first scientist onboard. We understood for the first time the real origins of pathologic blood coagulation, which led us to start a company that addressed coagulopathy in cardiovascular disease. This was a great experience.

One day in 1996 I received a call from Michael Milken's office. He had formed a foundation several years before (CaP CURE, which was renamed as the PCF) that was growing and was focused on funding research to improve treatments for advanced prostate

COPYRIGHT @ 2020 by the Society of Nuclear Medicine and Molecular Imaging. cancer. He wanted a full-time scientist to leverage the funded science and to create a scientific community. I decided to join. It was going to be a 5-year project. This was in 1997, and I am still doing it because I enjoy it so much and have had the privilege to be part of an enterprise that has improved the lives of men with prostate cancer. I am proud to be the PCF Chief Science Officer.

Dr. Czernin: What was Mr. Milk-

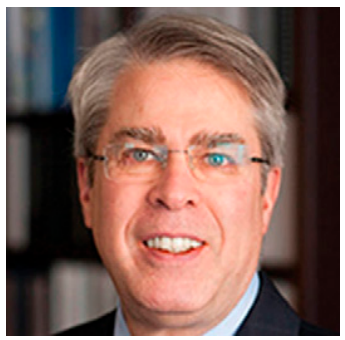

Howard R. Soule, PhD en's motivation to start the foundation?

Dr. Soule: He was diagnosed in 1993 with a very aggressive prostate cancer. Fortunately, it responded well to medical treatment, and he remains disease free to this date. Mike dedicated himself to changing history for all men with prostate cancer. And that's what our foundation has done.

Dr. Czernin: The foundation raised enormous funds for research. How did you initiate the growth process of the foundation?

Dr. Soule: The key was to attract donors and individuals with concern for the disease and developing a group that was expert in fundraising - among them Jonathan Simons as our CEO. He is a great physician, scientist, and friend, and he's also done a remarkable job of fundraising. The foundation has raised more than $\$ 800$ million dollars and has funded more than 2,000 projects in 22 countries.

Dr. Czernin: And do you use a peer-review process that mimics National Institutes of Health (NIH) standards?

Dr. Soule: PCF uses a rigorous peer-review system, but the process is streamlined compared with that of the government. Applications are less complex, and the time to funding is reduced.

Dr. Czernin: New drugs for many cancers are becoming available and often we see incremental improvements in overall survival or progression-free survival. Often these benefits are marginal. You always emphasize that we need to aim for cure rather than for incremental improvements. What is your vision on how to get from improvements to cure?

Dr. Soule: Well, one is to better understand the disease. We probably think we know a lot more about human malignancy than we actually do. We need a strong investment in basic science research. This should be and is the focus of the DOD and the NIH. Our sweet spot is the translation of those ideas into therapies. In the late 1990s and early 2000s we probably funded 2 dozen phase 2 trials of combination chemotherapies that led to the conclusion that prostate cancer was taxane sensitive. This led to the development of docetaxel, which was the first life-prolonging therapy for advanced prostate cancer. We also saw the wisdom of Charles Sawyers, who went against the grain and believed that the androgen receptor was still active, mutated, or overexpressed 
in castration-resistant prostate cancer. We made a relatively small contribution to Charles that resulted in the discovery of enzalutamide, an important life-prolonging therapy for advanced prostate cancer patients. In fact, every single Food and Drug Administration (FDA)-approved life-prolonging or -improving therapy for advanced prostate cancer has PCF fingerprints all over it. We were the ones that came in early and funded projects that in some cases were considered too radical for traditional funding agencies.

Dr. Czernin: In the United States you are a trailblazing organization for radioligand therapy (RLT) in combination with other therapeutics to make an even more significant impact on survival. How did you get exposed to the concept of RLT and specifically prostate-specific membrane antigen (PSMA)-targeted theranostics?

Dr. Soule: I would have to give the honor to Neil Bander at Weill Cornell. Dr. Bander has been continuously funded by the foundation for a very long time. And he was the one who did the first translational studies in academia on monoclonal antibodies and small-molecule ligands targeting PSMA.

Dr. Czernin: You have pointed to the great potential of RLT. Diagnostic PSMA ligands are going to be approved by the FDA country. The centers of excellence are those VA hospitals with strong ties to leading academic medical centers, such as UCLA with the West LA VA and the University of Washington with the Puget Sound VA. These are only 2 examples of our 10 VA Centers of Excellence. We are providing infrastructure funding to VA hospitals in order to allow them to practice precision medicine for veterans with advanced prostate cancer. We believe that veterans should be treated as well or better than the general population. The research opportunities in the VA system are enormous and stand on the shoulders of a single electronic medical record and advanced bioinformatic tools.

The second question addressed the poor outcomes in minority patients. It actually turns out that minority patients do fine when they're treated in the VA, because there is access to a standard of care that is evidence based and uniform across the VA system. The increased death rates in African American men affected by prostate cancer in the community are not observed when treated in the VA system. This observation is linked to access to care. However, there is an increased incidence of prostate cancer in this minority population. More needs to be done in terms of policy and under-

\section{"Money is always at the center of the situation, but money doesn't generate good ideas. Money facilitates the application of good ideas."}

soon, we hope. The VISION trial (VISION: An International, Prospective, Open Label, Multicenter, Randomized phase 3 Study of ${ }^{177}$ Lu-PSMA-617 in the Treatment of Patients With Progressive PSMA-Positive Metastatic Castration-Resistant Prostate Cancer) is coming to closure, and we all hope that the results will be positive. What do you see as the role and position of these treatments?

Dr. Soule: We've taken a real global perspective on RLT. We fund science at the University of California at Los Angeles (UCLA), Weill Cornell, and at the Peter MacCallum Cancer Centre in Melbourne, Australia. It truly is a global consortium of clinical trials and translational science. Once PSMA imaging is generally available, physicians will do a better job of staging prostate cancer. We're also hopeful that it will greatly aid in detecting sites of biochemical recurrence. This could lead to earlier and more accurate interventions.

The question is how to address heterogeneity and changes in PSMA expression both within and among metastatic deposits. For this reason, PSMA-based RLT is likely going to require a treatment partner. Many clinical trials are combining RLT with inhibitors of DNA damage response and repair, such poly ADP ribose polymerase (PARP) inhibitors. Different isotopes, $\alpha$ and $\beta$ emitters, are being tested, and dose and schedule are getting optimized. There is a lot of activity right now, and I think in the next several years we're going to have a better idea of how this therapy could change everything for patients. PCF is funding aggressively in this area

Dr. Czernin: An important focus of PCF is to understand the diversity of the population that suffers from prostate cancer and how we can achieve better health care. You have a very close relationship with the Veterans Administration (VA). You also understand that African American males have a higher incidence of prostate cancer and worse outcomes. Can you comment on these issues?

Dr. Soule: Our program with the VA was really spearheaded by Mike Milken and Jonathan Simons. We identified centers of excellence in the huge VA hospital system, the largest in our standing issues related to disparities in access to care. But there's also a biologic component that has not been completely understood in African American men, related to increased risk of diagnosis of the disease. PCF is focused on discovering precision detection methods that will help identify those African American men at very high risk for prostate cancer.

Dr. Czernin: I want to switch gears for a moment and ask about your leadership structure in this very successful foundation. Is Mr. Milken closely involved in all decisions, or do you adopt a more decentralized approach?

Dr. Soule: Mike Milken is the founder and chair of the organization. We have a very strong, supportive, and scientifically engaged board of directors. As chair of the board, Mr. Milken is very involved at the highest level of our strategic planning and fundraising. He's been the catalyst for really everything related to the growth and sustainability of the foundation. The man is indefatigable, to say the least. He has done so many great things in philanthropy over the years, not only in medical research but also for education, the arts, and many, many other areas. Mike is not involved in our day-to-day operations; that's really run by a leadership team with Jonathan Simons as the CEO.

Dr. Czernin: When you look ahead to the next 10 years, what do you think will be the key innovation in prostate cancer research that moves us closer to cure? What are the major limitations and roadblocks to get to cure? Is it primarily an issue of funding?

Dr. Soule: I think we're getting pretty close. It is clear that men are living longer with metastatic prostate cancer. But the work isn't finished until the mortality rate goes to zero. Amazing innovations are going to reduce the mortality, and RLT is likely one of them. I firmly believe we're going to figure out immunotherapy in prostate cancer. There are going to be innovative new bispecific antibodies, and antibody drug conjugates to non-PSMA targets are in various stages of clinical assessment. I think eventually artificial 
intelligence is going to make an impact on improved treatments and overall survival in prostate cancer and in all of oncology. These are just a few ideas.

Money is always at the center of the situation, but money doesn't generate good ideas. Money facilitates the application of good ideas. We should all advocate for more government money and more foundation money, because that's what puts people to work on solutions to biomedical problems. The paylines are too low, and good science for patients is left on the table every year at foundations and government agencies. As a nation we need to finance medical research much more actively than we do today, and that is a major limitation in our progress.

Dr. Czernin: To paraphrase John F. Kennedy: Ask not what the PCF can do for the community, ask what the community can do for the PCF? What would be on top of your wish list?

Dr. Soule: First of all, every year, send us your best ideas. We want everybody's best idea. The foundation has some wisdom. We are pretty thoroughly rounded scientists. But we need the ideas from the community. So that's number one. Second, we need to continue to recruit new people from outside the prostate cancer arena-people with new ideas-new ways to examine the problems. More than money, we need ideas. And finally, in all of cancer research, we need to fund teams of hard-working and innovative investigators. The problems are too complicated to be solved by an individual. We need armies of people focused tirelessly.

Dr. Czernin: Is there any anything else that you want to convey to our readers?

Dr. Soule: I have never been more hopeful that we are going to find a solution to this disease, and we're so thankful that nuclear medicine with its engaged physicians has joined. You are a new discipline to our foundation. And we are so pleased to have that discipline in our family helping us find a solution to the problem.

Dr. Czernin: Thank you very much, Howard. The readers will really be grateful for your time and your insights.

\section{DISCLOSURE}

Johannes Czernin is the recipient of two Challenge Awards from the Prostate Cancer Foundation. No other potential conflict of interest relevant to this article was reported. 